\title{
Comparison of Visuospatial Skill Development Between Preclinical and Clinical Undergraduate Students Using Dentinal Pin Placement Exercise
}

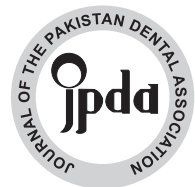

\author{
Alia Ahmed ${ }^{1}$ \\ BDS FCPS \\ Usman Anwer Bhatti ${ }^{2}$ \\ BDS, FCPS
}

OBJECTIVE: The objective of this study was to compare visuospatial and psychomotor skills of second year pre-clinical dental students with final year dental students using an exercise in dentinal pin placement.

METHODOLOGY:A total of 120 BDS undergraduate students who had completed second or final year Operative dentistry rotation were included. While students from second and final year who had not consented to participate or had missed the practical demonstration or whose dentinal pins were misplaced after becoming loose from the tooth were excluded. Participating students placed the dentinal pins, following which Adobe Photoshop (version CC 2014) was used to analyze the photographs of the taken radiographs in two dimensions. Parameters assessed were pulpal perforations, periodontal perforations and pin angulation. Independent sample t-test was used to compare continuous variables while chi-square test was used for testing association for categorical variables.

RESULTS: Final year students fared better in all categories of pin placement except periodontal perforation which was the same for both years. Statistically significant difference in the angulation for pin placement were observed between the two student groups in mesiodistal direction ( $\mathrm{p}$ value $=0.001$ ) and in buccolingual direction ( $\mathrm{p}$ value <.001).

CONCLUSION: There is a significant difference in the psychomotor and visuospatial skill of second year pre-clinical when compared with the final year clinical undergraduate students.

KEYWORDS: curriculum, dental, learning, operative, students.

HOW TO CITE: Ahmed A, Bhatti UA. Comparison of visuospatial skill development between preclinical and clinical undergraduate students using dentinal pin placement exercise. J Pak Dent Assoc 2021;30(3):147-151.

DOI: https://doi.org/10.25301/JPDA.303.147

Received: 23 November 2020, Accepted: 20 May 2021

\section{INTRODUCTION}

$\mathrm{T}$ he effective and safe execution of a dental procedure requires an understanding of the natural anatomy and a certain level of manual dexterity. As part of the preclinical training for Operative dentistry, dental students are trained to develop the necessary psychomotor skills to prepare precise geometric shapes in the natural tooth without damaging the supporting biological structures like the pulp and periodontium. A spatial appreciation of the normal pulp chamber and other anatomic landmarks like dentinoenamel junction is necessary for preventing such an iatrogenic damage. ${ }^{1}$

The dental students must learn a variety of clinical procedures which require a varying degree of psychomotor skill. Most of these procedures have to be carried out with

1. Professor, Department of Operative Dentistry, Islamic International Dental College, Riphah International University, Islamabad.

2. Assistant Professor, Department of Operative Dentistry, Riphah International University, Islamabad.

Corresponding author: "Prof. Alia Ahmed" < Alia.Ahmed@ riphah.edu.pk > compromised vision. These procedures are made effective and safe by gathering pre operative radiograph information. This information coupled with the anatomic understanding allows recognition and respect for spatial arrangement of biological structures.

The desired end result of pre-clinical instruction and clinical training for dental students improvement of manual dexterity in relation to dental procedures. ${ }^{2}$ Many skills, like the ability to interpret a radiograph helps in procedures which require preoperative assessment, are important to prevent iatrogenic damage and ensure patient safety.

Hence it is important to know if the current Operative Dentistry curriculum in Pakistan contributes to an improvement in complex visuospatial and psychomotor skills. Is the psychomotor domain of learning being adequately addressed? Are necessary skills being imparted to make them safe for clinical work, for example the ability to judge the position of the dental pulp within the tooth to avoid accidental perforation during clinical procedures?

Hence, the objective of this study was to compare the difference in visuospatial and psychomotor skills between 
dental students of second year pre-clinical and final year clinical level using an exercise in dentinal pin placement.

\section{METHODOLOGY}

This was a cross-sectional comparative study. The study was carried out at the phantom head laboratory of Islamic International Dental College. Esthical approval was obtained Ref No. (11DC/IRC/2019/09/002). About 120 BDS undergraduate students comprising of 60 second year and 60 final year students were selected from a total of 150 students for participation in this study. Among the 150 students, 30 were excluded according to the exclusion criteria. Convenience sampling was carried out when recruiting the students for the study. Informed consent was taken from the students to participate in the study. The objectives of the study were clearly explained and anonymity was assured by only assigning numeric coding to the submitted sample.

Inclusion criteria were all those students who had either completed second or final year Operative dentistry rotation for the respective year.

Exclusion criteria were students from second and final year who had not consented to participate in the study, who had missed the practical demonstration session and whose dentinal pins were misplaced after becoming loose from the tooth.

Both second and final year students placed dentinal pins in the tooth for the first time. Neither of them had previous experience in placing dentinal pins before this at a preclinical or clinical level. Participating students were asked to view a pre-placement radiograph that was taken buccolingually. They were explained the steps of placement followed by the criteria by which to judge the placement. This was done first by a 30-minute traditional lecture followed by a 15 minutes practical demonstration of the procedure by a clinical instructor with over 20 years of teaching experience (AA). Extracted mandibular and maxillary molars were prepared for the task by reducing the tooth structure near an intact transitional line angle using a straight fissure diamond bur (SF 21- Mani). Tooth reduction was done to the level of $1 \mathrm{~mm}$ above cementoenamel junction to allow easy visualization of dentinoenamel junction and simulate clinical situations requiring dentinal pin placement. Care was taken to avoid any pulp exposure. A single operator (UA) prepared the teeth to simulate clinical situation. The completed preparations were evaluated for adequacy by second operator (AA) before distributing among the students participating in the study. Those preparations which were found unacceptable were discarded and then new teeth were prepared to replenish the sample.

Students were then asked to place the dentinal pins
Figure 1: Extracted tooth embedded in self caure acrylic with pin inserted into the dentin

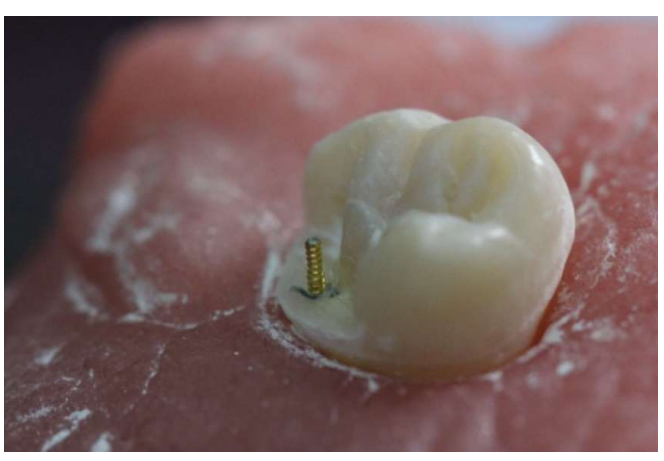

according to the delivered demonstration (Figure1). Following which two radiographs, one in buccolingual orientation and another in mesiodistal orientation were taken. The radiographs were taken by placing the teeth over the periapical films (E-Speed Kodak) and with the beam aligned to right angles of the tooths long axis. The processed radiographs were evaluated for quality by the operators AA (Alia Ahmed) and UA (Usman Anwer) and inadequate radiographs were re-taken. The radiographic films were arranged on an illuminator and then photographs were taken using a digital camera (EOS-60D, Canon) at settings of ISO 100, 1/50 and f8. Adobe Photoshop (version CC 2014) was used to analyze the photographs of the obtained radiographs. An optimally developed and fixed radiograph was selected by mutual agreement of the evaluators for reference during image standardization in Adobe. The image of this selected radiograph was imported in Adobe and then image adjustment tool was used to adjust each evaluated image to match the appearance of this standardized image before recording any measurements.

Using a line tool two lines were drawn, one parallel to the placed pin and the other parallel with the external surface of the root. A protractor was imported and superimposed over the images of radiographs and the angulation was

Figure 2: Radiographs showing angulation of pin with respect to the outersurface of the tooth in mediodistal (left) and buccolingual view (right)
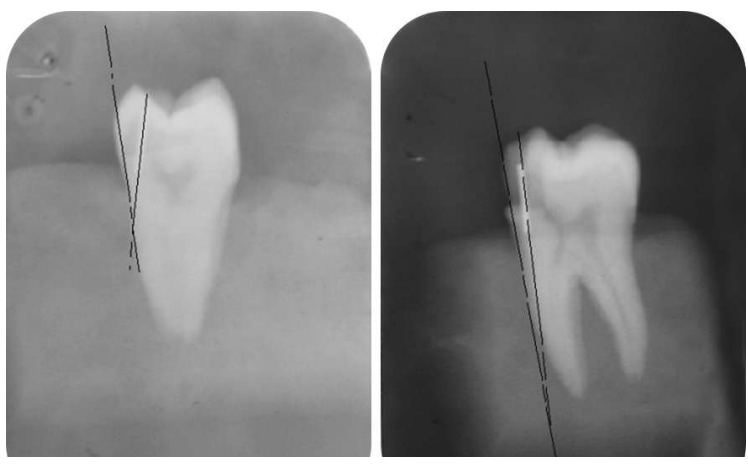
recorded between the two lines. Figure 2 shows how the angulations of pin with respect to the external surface were measured. Perforations in the pulp were identified on the radiographs while perforations in the periodontium were evaluated clinically as visible extensions on the root surface. The linear and angular measurements were recorded after agreement among the evaluators (AA and UA). Angulations in both the buccolingual and mesiodistal dimension were noted and compared. Looseness of the pin was detected by applying gentle withdrawal force using tweezer (College serrated handle- Precision dental). Depending on whether the pin was displaced on not it was looseness was reported as present or absent respectively.

The statistical analysis was done by Statistical Package for Social Sciences (version 17). Independent sample t-test was used to compare the differences between second and final year students for pin angulation. Chi square test was used to analyze the differences for looseness of the pin, and perforation into pulp or periodontium.

\section{RESULTS}

Final year students fared better in all categories of pin placement except periodontal perforation which was the same for both second and final year students. Perforations, looseness and angulations were significantly better for final year students with the p-value set at 0.05 (Table.1). There was a lower rate of perforation into the pulp, which was highly significant at a $\mathrm{p}$ value $<0.001$.

Table 1: Comparison of dexterity measures among second and final year students

\begin{tabular}{|c|c|c|c|}
\hline Measure of manual dexterity & $\begin{array}{c}\text { Second year } \\
\text { students }(n=60)\end{array}$ & $\begin{array}{c}\text { Final year } \\
\text { students }(n=60)\end{array}$ & -value \\
\hline Pulp perforation & $25 \%$ & $0 \%$ & 0.001 \\
\hline Periodontal perforation & $0 \%$ & $0 \%$ & $>0.05$ \\
\hline Looseness & $32 \%$ & $4.5 \%$ & .00 \\
\hline $\begin{array}{c}\text { Angle with the surface of the } \\
\text { tooth (mesiodistal view) }\end{array}$ & $\begin{array}{c}8.29^{\circ} \pm 4.77 \\
(\text { mean) }\end{array}$ & $\begin{array}{c}4.48^{\circ} \pm 7.01 \\
\text { (mean) }\end{array}$ & 0.001 \\
\hline $\begin{array}{c}\text { Angle with the surface of the } \\
\text { tooth (buccolingual view) }\end{array}$ & $\begin{array}{c}11.05^{\circ} \pm 8.54 \\
\text { (mean) }\end{array}$ & $\begin{array}{c}3.90^{\circ} \pm 4.63 \\
\text { (mean) }\end{array}$ & 0.000 \\
\hline
\end{tabular}

Figure 3 highlights the angulations of placed pins with the ideal angulation being zero. Pins placed by final year students were more parallel to the surface of the tooth and had fewer extreme outliers with a more pronounced in the buccolingual direction.

There was a significant difference in the angulation of the placed pin for second year $(11.05 \pm 8.54)$ versus final year $(3.90 \pm 4.63)$ in the mesiodistal direction $(\mathrm{p}$ value $=0.001)$.

There was also a significant difference in the angulation of the placed pin for second year $(8.29 \pm 4.77)$ versus final year $(4.48 \pm 7.01)$ in the buccolingual direction ( $\mathrm{p}$ value $=0.000$ ).
Table 2: Boxplot showing the angulations of pin placement from the surface of tooth

MDA2: mesio-distal angulation for second year students, MDA4: mesio-distal angulation for final year students,

BLA2: bucco-lingual angulation for second year students,

BLA4: bucco-lingual angulation for final year students

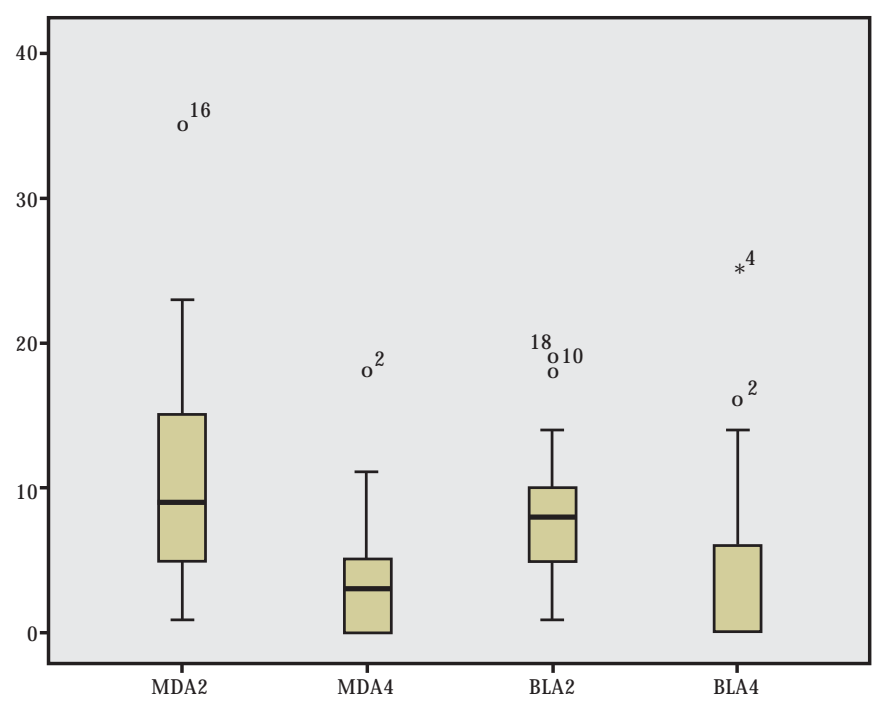

\section{DISCUSSION}

This study utilized a simple simulated dental restorative procedure to see if and how psychomotor skills are improved between second and final year. Many tests of manual dexterity have been used but for dental students ${ }^{3}$ it is more relevant to use a method which can evaluate many variables of dexterity and visuospatial judgment related to dental clinical procedures simultaneously. It should also be a procedure commonly practiced in the usual range of clinical procedures. Dentinal pins are used for auxiliary retention for grossly carious teeth and to retain cores. ${ }^{4-8}$ They have become increasingly less used as bonding techniques have become more predictable.

Pre-clinical instruction aims to prepare the student to perform procedures on the patient, however, the correlation between pre-clinical and clinical grades have not shown to be significantly correlated. ${ }^{9-11}$ Manual dexterity ratings of dentists and the general public have been assessed as being essentially the same, ${ }^{12}$ yet in order to be a good dentist certain procedures demand a high level skill which must be learned by training. A good level of manual dexterity has been shown to be associated with better pre-clinical grades. ${ }^{13}$ But the complexity of dental procedures suggests that it is more than just dexterity which predicts a dentist's performance. Lugassy et al were not using the simple manual dexterity test, but a modification in which indirect vision 
was used to perform the task. This emphasizes another skill, the ability to work in an area where direct vision is not possible. There are many such areas in the human oral cavity, one being a pulp space which is not directly visible but must be protected from iatrogenic injury. These are the skills which can be learned. ${ }^{14}$

Alternatively, Chambers et al. observed in his study of 465 students that simple repetition of a skill didn't translate into improvement of competency. He failed to observe a pattern of relationship between prior experience and improved clinical performance, questioning the validity of clinical evaluation solely based on quality of clinical work. The findings of this research however revealed an improvement in performance of a task with experience. ${ }^{15}$

Final year students performed better in all categories of dexterity evaluation except perforation into the periodontium where the performance was the same. This can be due to the difference in the number of hours spent in development of motor skills and a greater exposure to practical procedures. Also its important to note that different students have different learning curves and this possibly influences psychomotor skill development. ${ }^{2}$

This study addressed the difference in visuospatial skills by identifying chances of error between pre-clinical and clinical level students when doing a certain procedure. There were few limitations of the study like for instance the sample was restricted to a single teaching college and could not be considered representative of the dental student population in Pakistan. Moreover, the cross-sectional nature of the study makes it difficult to credit the identified difference in skills to curriculum. The variation in sample like accumulation of students with better innate skills in a particular batch can also affect the results. Despite the limitations the strength of the study is that a clinical task with high fidelity was used for assessing the visuospatial skill rather than traditional psychometric tests. However, longitudinally designed studies utilizing multiple modes of dexterity and visuospatial skill evaluations are required to ascertain the true level of enhancement.

\section{CONCLUSION}

A significant difference in the psychomotor and visuospatial skills was observed between the second year pre-clinical and final year clinical undergraduate students especially the judgment of pulp position from the periapical radiograph. More studies are required to find out the complex set of skills necessary to be acquired by students to practice safe restorative dentistry. Future research may be targeted towards identifying those interventions which result in greater learning in the psychomotor domain.

\section{CONFLICT OF INTEREST}

The authors deny any financial interest in the subject matter or materials discussed in the article.

\section{REFERENCES}

1. Schwibbe A, Kothe C, Hampe W, Konradt U. Acquisition of dental skills in preclinical technique courses: influence of spatial and manual abilities. Adv Health Sci Educ Theory Pract. 2016;21:841-57. https://doi.org/10.1007/s10459-016-9670-0

2. Ben-Gal G, Katorza L, Weiss EI, Ziv A. Testing motor learning curves among dental students. J Dent Educ. 2017;81:1171-178. https://doi.org/10.21815/JDE.017.076

3. Gallagher AG, Leonard G, Traynor OJ. Role and feasibility of psychomotor and dexterity testing in selection for surgical training. In: ANZ J Surgery. 2009;79:108-13.

https://doi.org/10.1111/j.1445-2197.2008.04824.x

4. Wilson PHR, Fisher NL, Bartlett DW. Direct cores for vital teeth-materials and methods used to retain cores in vital teeth. Eur J Prosthodont Restor Dent. 2002;10:157-62.

5. Wassell RW, Smart ER, St George G. Crowns and other extracoronal restorations: cores for teeth with vital pulps. Br Dent J. 2002;192:499-502, 505-9.

https://doi.org/10.1038/sj.bdj.4801411

6. Kao EC. Fracture resistance of pin-retained amalgam, composite resin, and alloy-reinforced glass ionomer core materials. J Prosthet Dent. 1991;66:463-71.

https://doi.org/10.1016/0022-3913(91)90506-R

7. Haller B, Götze W, Weiss G. Parapulpal pins and their effects on the fracture resistance of pin-retained cores. J Oral Rehabil. 1991;18:45969.

https://doi.org/10.1111/j.1365-2842.1991.tb01691.x

8. Šegovic S, Ferk S, Anic I, Jukic S, Galic N, Sistig S. Changes in dentin after insertion of self-threading titanium pins with 3 methods: A scanning electron microscope pilot study. J Prosthet Dent. 2002;87:182-8.

https://doi.org/10.1067/mpr.2002.120652

9. Hauser AM, Bowen DM. Primer on preclinical instruction and evaluation. J Dent Educ. 2009;73:390-98.

https://doi.org/10.1002/j.0022-0337.2009.73.3.tb04711.x

10. Simon JF, Chambers DW. The search for a profile of aptitudes that characterize dentists. J Dent Educ. 1992;56:317-21. https://doi.org/10.1002/j.0022-0337.1992.56.5.tb02640.x

11. Fernández-Pabón JJ, Soderstrom EJ, Chambers DW. Prediction of success in dental school on the basis of dental aptitude test scores and other variables. J Dent Educ. 1968;32:261-71. https://doi.org/10.1002/j.0022-0337.1968.32.3.tb00103.x 
12. Lundergan WP, Lyon L. Research on hand dexterity and the practice of dentistry: reality and myth. J Am Coll Dent. 2007;74:15-6.

13. Lugassy D, Levanon Y, Pilo R, Shelly A, Rosen G, Meirowitz A, et al. Predicting the clinical performance of dental students with a manual dexterity test. PLoS One. 2018;13:e0193980.

https://doi.org/10.1371/journal.pone.0193980

14. Volet SE. Modelling and coaching of relevant metacognitive strategies for enhancing university students' learning. Learn Instr. 1991;1:319-36. https://doi.org/10.1016/0959-4752(91)90012-W

15. Chambers D. Learning curves: what do dental students learn from repeated practice of clinical procedures? J Dent Educ. 2012;76:291-302. https://doi.org/10.1002/j.0022-0337.2012.76.3.tb05258.x 